SHS Web of Conferences 10, 00050 (2014)

DOI: $10.1051 /$ shsconf $/ 20141000050$

C Owned by the authors, published by EDP Sciences, 2014

\title{
Brain research to ensure the safety of the public
}

\author{
A. Vilks \\ Rīga Stradinsš University, Latvia
}

\begin{abstract}
In our society, to-day human safety problems in prevention of public threats are increasingly gaining more and more attention. In the century of modern technologies, however paradoxical it could be, potential of safety in the society does not increase, while the level of threat increases, and the types, forms and negative consequences of threats expand. In the abuse of individuals, crime committing including, new innovative technologies are introduced, which are still not sufficiently recognized and studied. The aim of the author is to turn the attention to one of the possible new approaches in work of law enforcement authorities - psycho- and neurotechnologies and the topicality of the theme. The author points to the aspects of psychotechnological cognition and specific aspects of abuse, development outlines of neurolaw, as well as implementation practice of psychotechnology study courses and the possibilities in lawyers' professional education, not claiming to have a comprehensive and deep presentation of the topic. Psycho- and neurotechnology use in law enforcement authority work is comparatively new. Special services, however, have successfully used the corresponding technologies already at the beginning of the 20th century, although the history of psychotechnology use has more ancient roots.
\end{abstract}

\section{Topicality of problem}

The necessity to recognize the theme mentioned and possibilities for its studying are related to certain conditions. Firstly, new types of crime, as well as use of new techniques in committing crimes. Since there is a wide range of various method descriptions available on individuals' psychic offense, the courses have been established concerning the theme - psychotechnical methods are used in cases of fraud, theft of property, abuse of official position. Psychotechnologies are skilfully and actively used, applying modern technical means of communication (e-mail, "skype", mobile communication), doing practically anonymous communication, etc. Secondly, despite the wide accessability to new technologies in law enforcement authority work, they are not sufficiently widely used. In many cases the structures of the law enforcement authorities lack information about these technologies, the ways of their use and the effectiveness in crime prevention, identification of persons who have committed crimes, collecting factual evidence, as well as psychocorrection of criminals. Thirdly, single medical and interdisciplinary studies and research results, including neurology, could render completely new possibilities in recognition of persons and in correction of their antisocial and criminal behaviour. Fourthly, it is possible to use psychotechnologies, improving the unity of law enforcement

This is an Open Access article distributed under the terms of the Creative Commons Attribution License 4.0, which permits unrestricted use, distribution, and reproduction in any medium, provided the original work is properly cited. 


\section{SHS Web of Conferences}

authorities, internal mobility, professionalism, preventing psychotraumatism, "burn-out" syndrome, and deformation.

The use of psychotechnology in detection of crimes and their prevention is promising because due to its legal and medicinal approach, it makes it possible to develop a method of interdisciplinary use, as well as renders support, implementing the guidelines of legal policy, improving organizing potential of law enforcement authorities.

Neurotechnologies, in the last decade, have been developing very fast due to the new research methods for the investigation of a man, such as functional magnetic resonance tomography, magnetic encephalography, electroencephalography, infra-red spectroscopy, computer tomography, positron emission tomography. Lecturer Arturs Utinans of RSU Psychosomatic Medicine and Psychotherapy Department admits, that new neurological sciences can be used in predicting humans' individual behaviour, stating the increased aggressivity and antisocial personality features of prisoners (1). By means of corresponding technologies it would be possible to identify terrorists, or even pedophiles. Using visual image reconstruction of the human brain, it is possible to read human thoughts in the computer. Neurovisualization technologies have even formed a new branch - neurolaw.

In legal and medical practice, the so-called "brain fingerprinting" is being used more and more often. The method allows restoring and visualizing memory fragments, which are associated with a man's previous activity or conditions in which he/she has been. Magnetic stimulation contributes to the brain segment activation. By conducting an interview with an individual (interview, interrogation), one can see the person's reaction to certain words, phrases, pictures, things. The author of the technology of "Brain fingerprinting" is Lawrence Farwell. The method which is called "Mermer" was used as an evidence in the USA Iowa state in the case of Terry Harrington (2). Initially, he was accused of murder. Later, using "brain fingerprinting" method, the accused was found to have an alibi, but the witness who gave evidence about T. Harrington was found to be lying. "Brain fingerprinting" method is used to prove serial killer James B. Grinder's guilt in murdering of three women (3).

At the basis of "brain fingerprinting" method there is impulsive human brain response at subconscious level reacting to external stimuli in 300 miliseconds. For instance, showing a picture of a known person to an individual, the respective brain segment recognizes it. It is impossible to affect or control the psychic reactions of the brain. There is no need for an individual's verbal answer in the testing process. Electronic sensors which record reactions and transmit them to the computer are attached to the tested person's head. Stimulus to which the tested person reacts, can be like sounds, words, pictures, odour, things, computer picture (signs, symbols). Denial of recognition of stimuli only proves dishonesty of the person tested.

Neurojurisprudence is a new multidisciplinary science which includes law and neurology. The field deals with the use of neurological discoveries in law, studying, analyzing and evaluating legal phenomena, facts and legal subject behaviour models. In the international terminology, such terms as "Legal Neuroscience", "Law and Neuroscience", "Neurolaw", "Neurojurisprudence", as well as "Neurocriminology" are used. In neurojurisprudence, possibilities and limitations stating, to which extent neurological conclusions can be used in law are recognized.

Neurojurisprudence and its separate innovative approaches are mainly used in criminology, criminalistics and criminal process.

Within criminology, recognizing the mechanism of an individual criminal offense at neurology level, it is possible to study the effect of external social (micro) environmental conditions on an individual's psychic processes, status and properties. In criminology, it is important to study neurological signs of an individual's antisocial orientation, formation of deviations and motives. Not less important are the issues on one's individual legal awareness and culture formation process and its deformation. More and more achievements in neurology could be used in re-socialization probation service for persons who had done criminal offenses. Neurological methods could be used in accepting the newly-adopted legal acts at individual level. 


\section{Int. Conf. SOCIETY. HEALTH. WELFARE.}

Causes of individual criminal acts were earlier searched in the cranial anomalies, in human constitutional structure specificities, chromosomal pathologies, genetical deviations. Neurological approach is related to the recognition of causes of offensive behaviour in human brain, neurons.

In neurology, the serotonine's effect on a human's aggressive or depressive behaviour is studied. Serotonine is mentioned as the hormone for love and happiness, which is responsive for an individual's sense of happiness and welfare and emotional comfort. Study results gave evidence that the decrease of serotonine's level is contributing to an individual's increased aggressiveness or depression which could turn into suicidal manifestations. Both abuse against the environment, and autoabuse (suicides or their attempts) is a uniform determinant in serotonin's insufficiency in the human body.

In persons who have committed severe crimes (murder, severe physical abuse, rape, etc.) neurological study has fixed lowered serotonin level, consequently, such persons, on the basis of biological indices, are unable to do intentional purposeful activity. In general, they control their behaviour to a full extent. Such persons might be with diminished capacity and they could be applied a lesser penalty, in comparison to persons whose serotonine level is at normal level.

Considering the approach mentioned, it would be worth to know, whether the individuals, who have committed severe crimes, may have a medical examination, diagnosing their serotonine level or, by controlling the lower level of the mentioned substance, it would be possible to detect their diminished responsibility and capacity to control their behaviour.

A woman was found guilty in killing her fiancé. She was sentenced life imprisonment. No other evidence to prove the woman's guilt in the case was identified, except the woman's neurotechnological brain research. In research, the method of analysis of brain electrical oscillations signature -BEOS (Brain Electrical Oscillations Signature) was used. The respective research was carried out by Indian neurologist Champadi Ramanom Mukundanom (4).

BEOS method, based on encephalogramme data, gives a possibility to determine whether associations are formed in a human brain, and whether he/she thinks about the facts of certain events, which are reminded to him/her (told, shown). Known facts, activity or inactivity, when recognized, are "lighted up" as separate fragments in the brain and the person remembers again the events once experienced and felt. The method, at the same time, gives a chance to distinguish, what the individual has seen or done. It is admitted, that the above mentioned method can also say what a person is going to do, even antisocial and criminal intentions.

The USA president Barack Obama on April 2, 2013 announced, that a new scientific programme has been undertaken "Brain Research through Advancing Innovative Neurotechnologies" (5) - Brain Initiative. The aim of the programme is to acquire a human brain chart, in which all neurons and synapsis (neuron connections) would be included. The implementation realization term is ten years. Its financing is envisaged to be started from 2014, contributing 100 million US dollars for the programmes' primary development. At the end of 2013, the programme implementation plan had to be worked out. The primary programme objectives are: prevention and treatment of different diseases (Parkinson's disease, epilepsy, etc.). One of the possible project events is associated with rendering the aid to post-traumatic military operation veterans, persons with psychic disease forms. Perspective computer software, as a result of respective studies, would be able to react to human thoughts and manifestation forms. At the same time, the public is worried about the fact, that people's thoughts, feelings and activities could be corrected in an uncontrolled manner.

Research institutions of the European Union have agreed on the human brain research by implementing a project "Human Brain Project" (6). At the beginning of October, 2013, 135 participants from European research institutions met in Switzerland to agree on the development of ten-year-long Project (2014-2023). The total project costs are 1,2 billion EUR.

In 2012, the UK Royal Society announced, that the latest studies in the field of neurology will be used for the needs of the armed forces and special services (7). Neurological technologies are used in testing the draftees, deciding on their sending to service in the appropriate military troops, observation 


\section{SHS Web of Conferences}

of service course, and also during the post-traumatic rehabilitation process. Specialists admit, that more and more significant are becoming the issues on improvement of legal acts, which would better protect military officers and civilians from unfavourable psychotechnological effect.

The study course on psychotechnological law is implemented in the Faculty of Law in several foreign higher educational establishments. For instance, in Russian People's Friendship University, in the Departments of Criminal Law and Criminal Process is realized the Bachelor's study programme course "Current psychotechnology in law enforcement authorities" (8), the aim of which is to broaden students' professional competences, acquiring modern psychological methods and psychotechnological skills. The course objectives are: to make understanding in students on modern psychological psychotechnological methods, to be used in legal practice; to get acquainted with Russian and foreign experience in the use of psychotechnologies in crime prevention, crime detection and investigation, influencing different criminal groups (categories) and administration of law enforcement authorities; development of cooperation with psychologists, as well as learning communication skills in work with various client groups; development of professionally psychological features and their development; learning of psychological self-regulation skills; psychological readiness to use psychological innovations in legal practice.

The study course envisages 16 auditorium classes, including 8 lectures, 4 seminars, 4 practical classes. Students will have 20 academic hours of independent work.

A similar study course ("Psychotechnology in jurisprudence") is implemented also in Moscow State M.Sholohov Humanitarian University (9). The course is realized within the Master's study programme. It is envisaged to cover 73 academic hours, including 58 - independent work, 15 - auditorium classes. The content of the study programme is similar to that of Moscow People's Friendship University programme. Howerer, we can find some differences. In the Humanitarian University study programme has such themes as: demand of psychotechnological achievements of psychology in law; psychological provision of court action; psychology in penitentiary and postpenitentiary work; psychological aspects in the increase of effectivity in lawyers' work.

One has to mention, that many of themes included in the study courses "Current psychotechnologies in law enforcement authorities" and "Psychotechnologies in jurisprudence" would be useful not only for students, future lawyers, but also practicing police officers, procurators and court staff, the staff of the state probation service, penalty execution institution staff, etc. In case Rīga Stradiòš University staff and the heads of structural units, as well as the teaching staff of the Faculty of Law find interest in the problem, it would be possible to design and implement the corresponding study course there.

In some research institutions, there are trained specialists who are competent to apply psychotechnologies in crime prevention, collection of material evidence and detection of the offenders.

\section{Conclusion}

In the field of violation of the rights and in the criminal environment, one comes more and more in touch with psychotechnological attempts when committing crimes, such as fraud, murders, etc. Law enforcement authorities are trying to introduce the latest technologies (lie detector, vibroscanners, brain fingerprinting, etc.) in detection and prevention of crimes. In some study programmes of the Faculty of Law, there are also realized study courses on psychotechnologies. One has to admit, that for the investigation of brain activity,and for provision of public safety and fight with crimes, there should be paid much greater attention.

\section{References}

[1] Utināns A. Neirozinātnes policijas darbā http://www.rsu.lv/images/stories/dokumenti/ zinu_pielikumi/Programma_un_tezes_13092013_RED_GALA.pd. 
Int. Conf. SOCIETY. HEALTH. WELFARE.

[2] Dr. Larry Farwell - Inventor of Brain Fingerprinting. http://www . larryfarwell . com/brainfingerprinting-executive-summary-dr-larry-farwell-dr-lawrence-farwell.html.

[3] Farwell Brain Fingerprinting Catches a Serial Killer http://www.lawrencefarwell.com/ Fairfield - Ledger - serial - killer - dr - larry - farwell -brain-fingerprinting-drlawrence-farwell.html.

[4] Нейротехнологии отправили человека за решетку http://www.mobiledevice.ru/ brain-electrical-oscillations-signature-beos-champadi-raman-muku . aspx.

[5] BRAIN" Initiative http://www . whitehouse.gov/share/brain-initiativef.

[6] Human Brain Project "http://www. forbes.com/sites/jenniferhicks/2013/10/07/thehuman-brain-project-begins/".

[7] Brain Wawes Module 3, Conflict and Security http://royalsociety.org/policy/ projects/brain-waves/conflict-security/.

[8] Современные психотехнологии в правоохранительных органах web-local. rudn.ru/web-local/kaf/rj//files.php?f=pf.

[9] Психотехнологии в юриспруденции - МГГУ им. М.А.Шолохова//mggu-sh.ru/.../025. rp_psihotehnologii_v_yurisprudencii.d. 